\title{
Reflections on the use of Design Thinking and Service Design Tools to Improve Student Experience of an Online Learning Environment
}

Paul Devine

Nelson Marlborough Institute of Technology

Paul.Devine@,nmit.ac.nz

Submission Type: Brief Presentation (20mins $+10 \mathrm{minsQ} \& A)$

Keywords: Design Thinking, Online Learning Environments

\section{Abstract:}

Online learning technology offers many benefits to students and educators, but at the same time presents challenges and issues which can cause negative student experiences. These negative experiences may severely affect student learning, particularly for students who are studying remotely and may have complex causes. How does a small organisation understand, maintain, and enhance the student experience of increasingly complex online learning environments in an atmosphere of increasing student expectations?

Design Thinking and Service Design tools were used by the Learning Innovation and Insights (LII) Team at NMIT to examine their value in understanding and enhancing a challenging fully online course to improve student experience. This Action Research intervention had a profound effect on our thinking and practice as learning designers and technologists. Use of the user-centred Design Thinking tools and techniques challenged unwritten assumptions and helped the team gain understanding of the key factors and issues affecting the experience of the students on this course, and prioritise the change strategy required to improve it. The Service Design approach helped understanding of the students' changing needs over time. The artefacts produced by the tools proved helpful in untangling complexity, helped the team discuss and gain a shared understanding of the issues, and communicate issues to other stakeholders within the organisation.

There are significant implications for future practice of the LII Team at NMIT:

1. Design Thinking tools will be embedded in standard practice in the LII Team.

2. A widening priority from Learning Design to Learning Environment Design.

3. A refocus in the priority of LMS development from UI Design to UX Design, within a Service Design context.

4. A focus on adoption and use of "empathising" and listening tools and skills.

This presentation will focus on the use and impact of Design Thinking and Service Design tools and techniques such as the Hypothesis Map, the Journey Map, the Stakeholder Map, Personas and Extreme Users. 